\title{
Ensuring safety of home-produced eggs to control salmonellosis in Poland: lessons from an outbreak in September 2011
}

A Zielicka-Hardy (anna.zielicka@hotmail.co.uk) ${ }^{1,2}$, D Zarowna ${ }^{3}$, Szych4, G Madajczak ${ }^{4}$, M Sadkowska-Todys $^{1}$

1. National Institute of Public Health - National Institute of Hygiene, Department of Epidemiology, Warsaw, Poland

2. European Programme for Intervention Epidemiology Training (EPIET), European Centre for Disease Prevention and Control (ECDC), Stockholm, Sweden

3. District Sanitary Station, Department of Epidemiology, Otwock, Poland

4. National Institute of Public Health - National Institute of Hygiene, Department of Bacteriology, Warsaw, Poland

Implementation of control measures in line with European Commission regulations has led to a decrease in salmonellosis in the European Union since 2004. However, control programmes do not address laying hens whose eggs are produced for personal consumption or local sale. This article reports an investigatxion of a salmonellosis outbreak linked to home-produced eggs following a family event held in a farm in September 2011 near Warsaw, Poland. In the outbreak, 34 people developed gastroenteritis symptoms. Results from a cohort study indicated a cake, prepared from raw home-produced eggs, as the vehicle of the outbreak. Laboratory analysis identified Salmonella enterica serotype Enteritidis (S. Enteritidis) in stool samples or rectal swabs from 18 of 24 people and in two egg samples. As no food items remained, we used phage typing to link the source of the outbreak with the isolated strains. Seven $S$. Enteritidis strains analysed (five from attendees and two from eggs) were phage type 21c. Our findings resulted in culling of the infected laying hens and symptomatic pigeons housed next to the hens. Salmonella poses as a public health problem in Poland: control measures should not forget home-produced eggs, as there is a risk of infection from their consumption.

\section{Introduction}

In Europe, infection with Salmonella is a common cause of gastroenteritis [1]. Salmonella enterica serotype Enteritidis (S. Enteritidis) remains frequently reported, accounting in 2009 for $57 \%$ of all Salmonella serotypes [1]. Infection with $S$. Enteritidis is primarily linked to ingestion of contaminated meat or egg products [2]. Phage typing is a tool that is used to establish links between poultry flocks infected with $S$. Enteritidis and outbreaks among humans [3]. It can also be used to assess strains currently in circulation [4] and identify temporal trends [5]. It is not, however, routinely performed in many European countries, including Poland [4].
To prevent Salmonella infections, a number of control programmes have been implemented in the poultry industry within the European Union (EU) [1], including screening of laying hens, as recommended by the European Commission [6]. The introduction of programmes targeting laying hens has resulted in an overall decrease in the number of cases of Salmonella infection in the EU since 2004 [7]. However, under current regulations of the European Commission on the control of Salmonella, private farms producing table eggs (i.e. eggs produced or used for human consumption) for their own consumption or for sale to local retailers are exempt from current screening processes [8].

Despite the overall decrease in outbreaks of Salmonella infection in the EU, surveillance data since 1991 in Poland have shown that egg products play a pivotal role in the occurrence of salmonellosis outbreaks in humans, with $63 \%$ of the outbreaks between 2005 and 2010 being linked to this source [9]. The most striking increase has been in the proportion of outbreaks due to $S$. Enteritidis infection linked with the consumption of home-produced eggs: surveillance data show an increase from $76 \%$ of all $S$. Enteritidis outbreaks in 2004 to $82 \%$ in 2010 [9].

On 7 September 2011, a physician alerted the public health authority in Otwock, Poland, reporting that five people had fallen ill with gastroenteritis following a family event held three days earlier at a farm in the suburbs of Warsaw. The aim of our outbreak investigation was to stop the occurrence of cases, identify the source and explore ways to improve salmonellosis control in the long term at the household level. 


\section{Methods}

\section{Outbreak case definition}

We defined a probable case of gastroenteritis as a person who took part in the family event on 4 September 2011 or who ate food that was brought home from the event and then developed diarrhoea, vomiting, stomach ache or temperature higher than $39^{\circ} \mathrm{C}$ within 72 hours after consumption.

We defined a confirmed case of gastroenteritis as a probable case with laboratory confirmation of infection with S. Enteriditis.

\section{Descriptive epidemiology}

The hosts of the family event provided a list of addresses and contact numbers of all attendees of the family event. The public health authority collected information regarding demographics and health status of all the attendees and those identified during the outbreak investigation, in addition to a comprehensive list of all food and beverages consumed during lunch, dinner and dessert at the event. Initially, probable cases completed an open-ended, hypothesis-generating paper questionnaire: the majority were administered via telephone by the local authorities four days following the event. The questionnaire was a routine outbreak form, mainly focused on food consumption, with some additional questions regarding animal contact and travel within the previous two weeks. The National Institute of Public Health - National Institute of Hygiene then prepared a closed-ended questionnaire to be completed by all people on the list provided by the hosts and those identified during the investigation, to collect information on food/beverage items consumed during or after the family event and symptoms experienced. These close-ended questionnaires were administered, mainly via telephone, nine days after the event by each local health authority involved. Laboratory test results were added to the questionnaire results by the local health authorities or, in the case of phage typing, by the microbiology department at the National Institute in Warsaw.

\section{Analytical epidemiology}

We conducted a retrospective cohort study among attendees of the family event only. We calculated the risk of illness among people who had consumed food items and beverages, comparing this with the risk in people who had not consumed the same items. This yielded food/beverage-specific attack rates (ARs), relative risks (RRs) and $95 \%$ confidence intervals (Cls). We checked for effect modification and then established factors associated with becoming a case using multiple logistic regression. We included variables in the model if they had a $p$ value of less than 0.2. We excluded attendees identified as asymptomatically infected and those for whom basic information (e.g. age and items consumed at the event) was missing. Stata 10 was used for the statistical analysis [10].

\section{Laboratory investigation}

Human samples

Physicians collected stool specimens or rectal swabs from symptomatic and healthy people who consented (from 17 attendees and four people who ate food after the event). Local laboratories tested these samples for adenovirus, rotavirus and norovirus and cultured for Salmonella.

Antibiotic susceptibility profiles of Salmonella strains from four specimens were determined for treatment purposes $[11,12]$. These strains were from the first four cases, who lived in the farmhouse or surrounding houses on the premises

The laboratory at the National Institute of Public HealthNational Institute of Hygiene phage typed these same Salmonella strains cultured from stool specimens of the first four cases [13]. We identified phage types (PTs) using reference phages provided by the Health Protection Agency, Colindale, United Kingdom.

In addition, the public health authority collected stool specimens from two attendees who had been involved in the preparation of food for the event who lived on the premises where the event had been held (one of whom was a professional food handler). The strain from the stool culture of this professional food handler was also phage typed and the antibiotic susceptibility profile was determined. The health authorities also collected a stool specimen from an additional food handler who attended the family event, but did not take part in the food preparation. The reason for collection of specimens from these persons was to identify any asymptomatic infections that could have constituted sources of secondary infections or clusters.

Extended laboratory and environmental investigations The public health authority also requested information from the hosts regarding where the food had been prepared and stored, as well as details of the cold chain. In addition, the people involved in food preparation were asked about how the meals were served and the cutlery used during serving (e.g. knives).

Swabs were not taken from kitchen equipment at the event. As the event was held at a private residence, the taking of swabs in Poland is not currently required by law. In addition, the food safety authority visited the premises three days after the event, at which point the equipment had been cleaned. No left-over food items from the event were available for testing, thus phage typing of environmental and clinical isolates was used to identify the potential source of the outbreak. Raw eggs from the laying hens that resided on the farm had been used in food preparation for the event. As there were no samples available from the eggs used, fresh eggs from the flock were taken for laboratory analysis. 
No samples were taken from pigeons that lived in an aviary situated next to the laying hens.

Once the public health authority had received initial notification of the outbreak, they informed the local veterinarian, a legal requirement in Poland.

\section{Results}

An overview of the inclusion/exclusion criteria for the cohort analysis and the results of the laboratory analysis are shown in Figure 1.

\section{Descriptive epidemiology}

The event, held on 4 September, took place on the hosts' farm, where two families plus tenants lived $(n=11)$, in the farmhouse or surrounding houses on the premises. The hosts of the event kept 17 laying hens and 80 pigeons in adjacent aviaries.

A total of 57 people attended the event, of which 26 were symptomatic. Food taken home from the event was eaten later by eight people (all developed symptoms). Two attendees were involved in preparing food for the event (one of whom was a professional food handler). An additional food handler attended the event but was not involved in food preparation. All of those living on the farm premises $(n=11)$ attended the event.

In the open-ended (trawling) questionnaires administered to probable cases, we found that that numerous names were used for the cakes at the event, making it hard for us to compare the answers. Thus there was an intentional overlap between the open-ended and closed-ended questionnaires, to clarify any ambiguity.

The closed-ended questionnaire was administered to 65 people linked with the outbreak: 57 attendees (including the two people who prepared the food for the event) plus eight who ate food from the event later. We obtained information on sex and health status (healthy vs symptomatic) from all 65 people: if the person did not complete the questionnaire, the information was provided by the hosts or family members. The 65 people resided in six districts located in two provinces: $33 / 65$ were female.

Of the 65,18 were probable and 16 were confirmed cases. Symptoms of the 34 cases included diarrhoea $(n=32)$, temperature $>39{ }^{\circ} \mathrm{C}(n=26)$, vomiting $(n=22)$,

\section{FIGURE 1}

Inclusion/exclusion criteria for cohort analysis and results of laboratory analysis, Salmonella outbreak related to a family event, Warsaw, Poland, September 2011
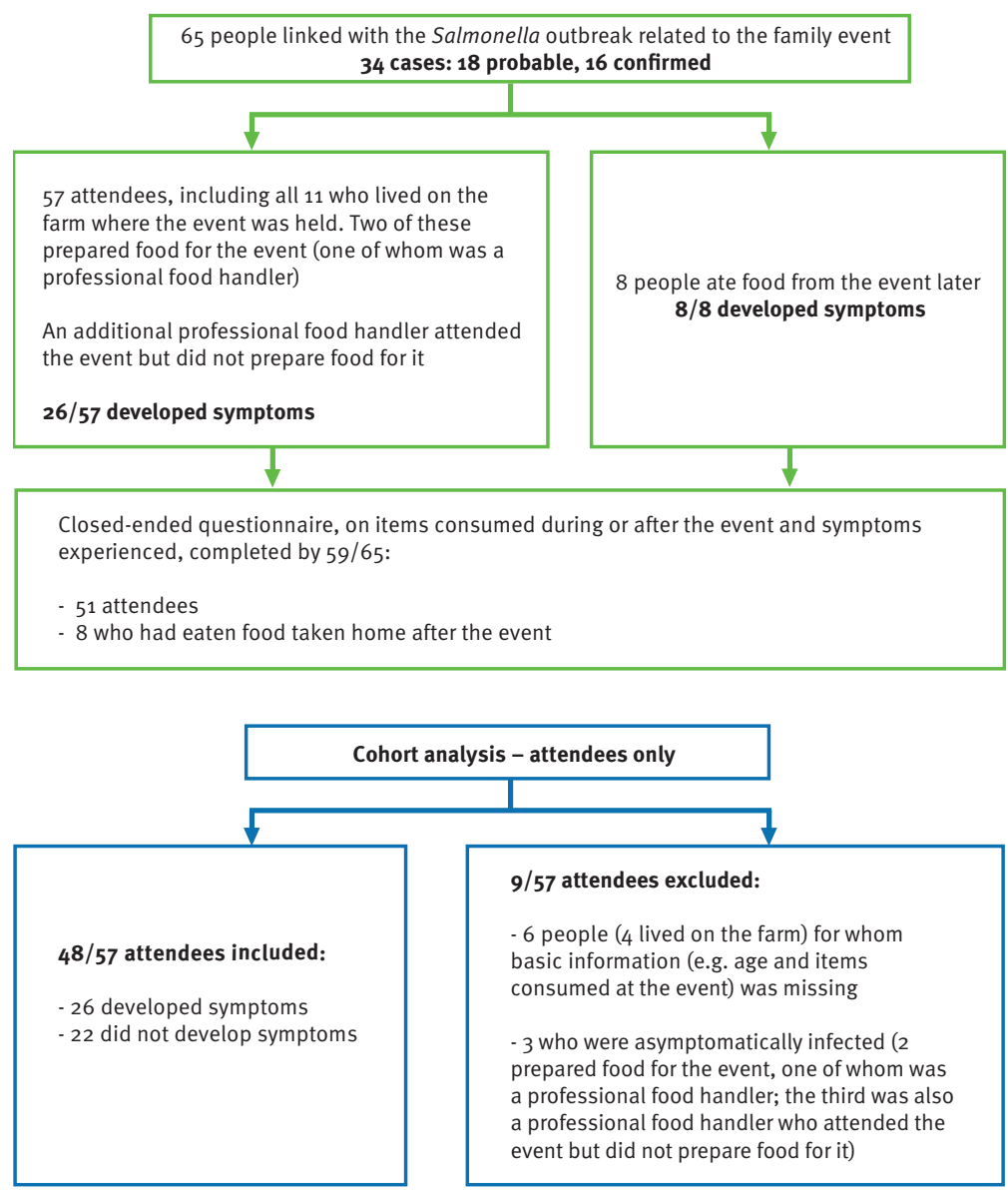

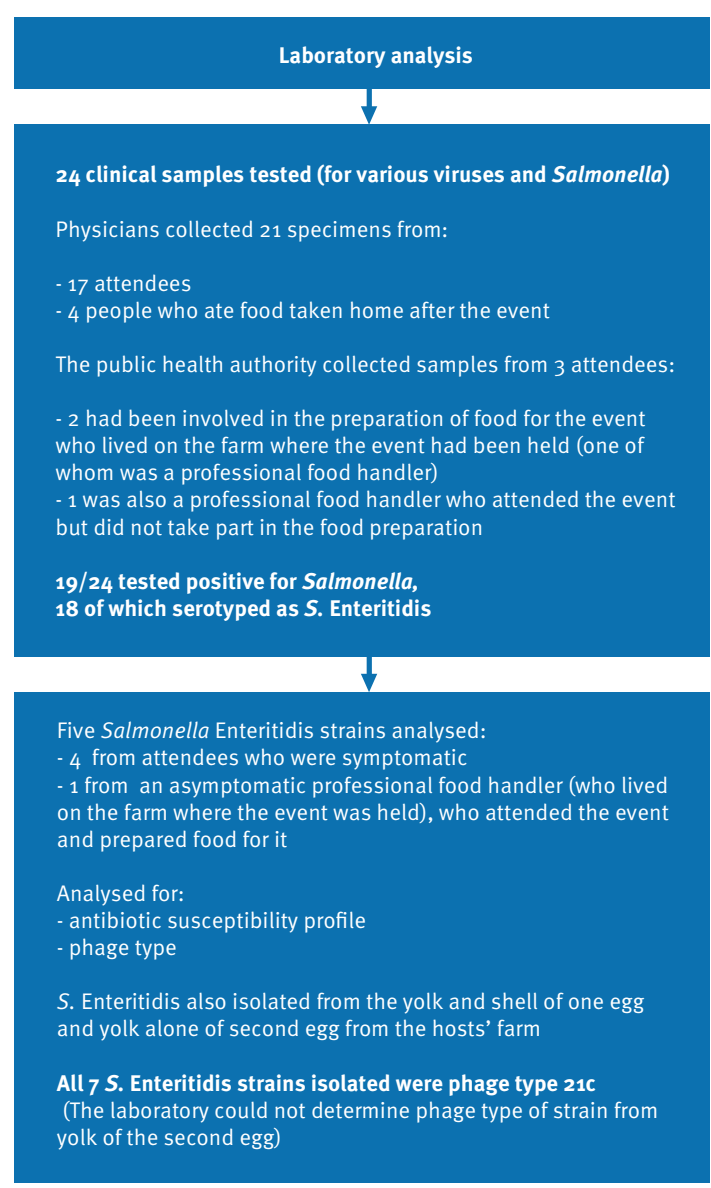


TABLE 1

Demographic details of people who attended ${ }^{\mathrm{a}}$ or ate food from a family event later, Warsaw, Poland, September 2011 $(\mathrm{n}=65)$

\begin{tabular}{|l|c|c|c|}
\hline $\begin{array}{l}\text { Demographic } \\
\text { information }\end{array}$ & Cases $^{\mathrm{b}}$ & Total & AR (\%) \\
\hline Age (years) & \multicolumn{5}{|l|}{} \\
\hline$<19$ & 9 & 14 & 64 \\
\hline $20-39$ & 12 & 22 & 55 \\
\hline $40-59$ & 7 & 13 & 54 \\
\hline$\geq 60$ & 6 & 10 & 60 \\
\hline Unknown & 0 & 6 & 0 \\
\hline Sex & 17 & 33 & 52 \\
\hline Female & 17 & 32 & 53 \\
\hline Male & & & \\
\hline
\end{tabular}

AR: attack rate.

Includes two attendees who prepared food for the event (one of whom was a professional food handler).

b Probable $(n=18)$ and confirmed $(n=16)$.

stomach cramps $(n=13)$ and nausea $(n=2)$. Four of the 34 were hospitalised.

The overall attack rate was $52 \%(34 / 65)$; the rates were similar in all age groups and by sex (Table 1 ).

A total of 59 people completed the close-ended questionnaires: 51 attendees (including the two food handlers), eight who had eaten food brought home after the event. Information on age was missing for six people: of the 59 who provided the information, the median age was 36 years (range: $4-88$ ).

The outbreak began on 4 September (the day of the event); the number of cases peaked between midnight and noon the following day and subsequently decreased (Figure). Time of symptom onset was provided by 29 cases: the remaining five could not recall the exact or approximate time. Of these 29 cases, 19 reported symptoms within 24 hours of the event (range: $3 \cdot 5^{-69}$ hours).

\section{Analytical epidemiology}

The cohort study comprised 48 attendees; nine attendees were excluded, in accordance with the criteria: six did not provide information on food consumption (four of whom lived on the farm) and three were asymptomatically infected with $S$. Enteritidis (two of whom lived on the farm). Of the 48 attendees, 26 developed symptoms (14 probable and 12 confirmed cases). People who ate angel cake (RR: 3.2; 95\% Cl: 1.7-6.2), cream cake (RR: $1.9 ; 95 \% \mathrm{Cl}: 1.4-2.6$ ) and caramel cake (RR: $1.8 ; 95 \% \mathrm{Cl}: 1.4-2.4$ ) were more likely to become ill (Table 2). Angel cake was eaten by most people in the cohort: 19 out of the 26 people who became ill ate it. Furthermore, three of four people who ate cream cake and/or caramel cake and became ill also ate angel cake. The remaining seven people who became ill but did not eat angel cake ate the following cakes: éclairs and cream cake $(n=1)$, éclairs only $(n=5)$ and a cake not on the list of food items collected $(n=1)$.

To explore whether cream cake or éclairs also acted as vehicles of infection, we examined the risk of developing symptoms for people who had eaten these cakes, according to whether they had eaten angel cake (Table 3). People who ate cream cake, but not angel cake, were four times more likely to become ill (RR: 4.00; $95 \% \mathrm{Cl}$ : 2.00-8.00). Consumption of éclairs was associated with a higher risk of illness, but this was not significant (RR: $4.71 ; 95 \% \mathrm{Cl}$ : 0.66-33.61). Stratification by caramel cake consumption was not possible because no one had been exposed to this cake alone.

Taking the results from our initial analysis into account, our multivariable model indicated consumption of angel cake as the only factor associated with illness (aOR: 192; 95\% Cl: 7-5,200) (Table 2). Cream cake was not included in the model as a result of colinearity.

\section{Laboratory investigation}

Human samples

A total of 24 rectal swabs/stool specimens were collected: physicians collected samples from 21 people (17 attendees and four from people who ate food after the event) and the public health authority collected samples from the three food handlers/people involved

\section{FIGURE 2}

Cases of gastroenteritis by time of symptom onset, Warsaw, Poland, September $2011(n=29)^{a}$

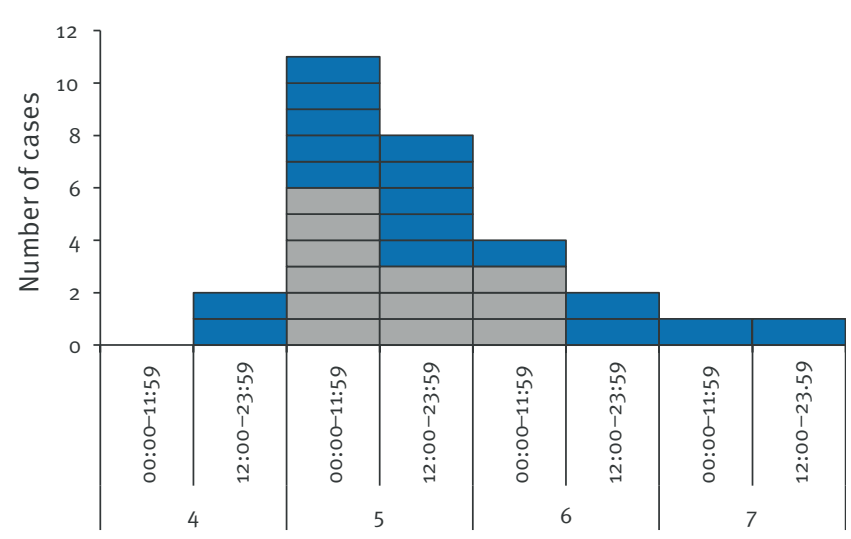

Date (September 2011) and time of symptom onset

Blue boxes represent probable cases (17 of 18 identified), grey boxes represent confirmed cases (12 of 16 identified).

a Time of symptom onset was unknown for five of the 34 cases. 
Attack rate of gastroenteritis according to consumption of food items and beverages among attendees at a family event, Warsaw, Poland, September $2011(\mathrm{n}=48)$

\begin{tabular}{|c|c|c|c|c|c|c|c|c|c|c|c|c|}
\hline \multirow{2}{*}{$\begin{array}{l}\text { Type of meal/ } \\
\text { beverage }\end{array}$} & \multirow{2}{*}{ Exposure $^{a}$} & \multicolumn{3}{|c|}{ Consumed } & \multicolumn{3}{|c|}{ Did not consume } & \multirow{2}{*}{$\mathrm{RR}$} & \multirow{2}{*}{$95 \% \mathrm{Cl}$} & \multirow{2}{*}{$\begin{array}{c}\mathrm{p} \\
\text { value }\end{array}$} & \multirow{2}{*}{$\mathrm{aOR}$} & \multirow{2}{*}{$95 \% \mathrm{Cl}$} \\
\hline & & Cases $^{b}$ & Total & AR (\%) & Cases $^{b}$ & Total & AR (\%) & & & & & \\
\hline \multirow{5}{*}{ Lunch } & Chicken soup & 9 & 14 & 64 & 17 & 32 & 53 & 1.2 & $0.7-2.0$ & 0.48 & - & - \\
\hline & Pork chop & 9 & 15 & 60 & 17 & 31 & 55 & 1.1 & $0.7-1.8$ & 0.74 & - & - \\
\hline & Tripe & 16 & 32 & 50 & 10 & 14 & 71 & 0.7 & $0.4-1.1$ & 0.18 & 0.1 & $0.01-1.7$ \\
\hline & Cabbage salad & 4 & 11 & 36 & 22 & 35 & 63 & 0.6 & $0.3-1.3$ & 0.12 & 0.1 & $0.004-2.8$ \\
\hline & Potatoes & 8 & 21 & 38 & 18 & 25 & 72 & 0.5 & $0.3-0.9$ & 0.02 & 0.1 & $0.01-1.3$ \\
\hline \multirow{2}{*}{ Dinner } & Chicken & 2 & 2 & 100 & 24 & 44 & 55 & 1.8 & $1.4-2.4$ & 0.21 & - & - \\
\hline & 'Bigos' (meat stew) & 5 & 6 & 83 & 21 & 40 & 53 & 1.6 & $1.0-2.5$ & 0.16 & 82 & $0.7^{-10,290}$ \\
\hline \multirow{5}{*}{ Dessert } & Angel cake & 19 & 21 & 91 & 7 & 25 & 28 & 3.2 & $1.7-6.2$ & 0.01 & 192 & $7-5,200$ \\
\hline & Cream cake $^{c}$ & 4 & 4 & 100 & 22 & 42 & 52 & 1.9 & $1.4-2.6$ & 0.07 & - & - \\
\hline & Caramel cake & 2 & 2 & 100 & 24 & 44 & 55 & 1.8 & $1.4-2.4$ & 0.21 & - & - \\
\hline & Apples in jelly & 5 & 7 & 71 & 21 & 39 & 54 & 1.3 & $0.8-2.3$ & 0.39 & - & - \\
\hline & Eclairs & 14 & 23 & 61 & 12 & 23 & 52 & 1.2 & $0.7-1.9$ & 0.55 & - & - \\
\hline Alcohol & Vodka & 4 & 9 & 44 & 3 & 12 & 25 & 1.8 & $0.5-6.0$ & 0.35 & - & - \\
\hline
\end{tabular}

aOR: adjusted odds ratio; $\mathrm{AR}$ : attack rate; $\mathrm{Cl}$ : confidence interval; RR: relative risk.

The shaded rows represent items for which $\mathrm{p}<0.2$ and were therefore included the multiple logistic regression model.

a Food items and beverages provided by the hosts.

b Probable $(n=14)$ and confirmed $(n=12)$.

c Not included in the multiple logistic regression model due to colinearity.

in food preparation who also attended the events. Of the 24,19 tested positive for Salmonella, 18 of which serotyped as $S$. Enteritidis (the 19th sample - from an attendee who did not live on the farm - was reported at Salmonella spp.). The laboratory did not identify any other pathogens in the samples, 17 of which were from attendees and four from people who ate food after the event.

Of the 18 serotyped strains, three were from attendees who did not have symptoms, two of whom were professional food handlers, one of whom was involved in food preparation for the event alongside the third asymptomatic individual. The public health authority exempted the two professional food handlers from work until they provided three consecutively negative samples.

Antimicrobial susceptibility profiles were determined for the same five strains that were phage typed. All were fully sensitive to ciprofloxacin, furazolidone, trimethoprim/sulfamethoxazole and had medium sensitivity to ampicillin and amoxicillin/clavulanic acid.

These same five strains of $S$. Enteritidis were phage typed as 21C. Apart from the strains isolated from the egg samples (described below), no other strains were phage typed due to financial constraints.
Extended laboratory and environmental investigations $S$. Enteritidis was also isolated from the yolk and shell of one egg and the yolk alone of a second taken from the event hosts' laying hens. Two Salmonella strains isolated from the first egg were phage typed as 21c. The laboratory could not determine the phage type of the strain isolated from the yolk of the second egg.

The hosts used raw eggs, collected four days before the event from their laying hens, in the preparation of a quadruple cream-layered angel cake. During inspection by the public health authority, the hosts explained that all cakes had been stored at room temperature alongside other dishes on a warm autumn day. All cakes had been set out on the table on the same serving plate along with one knife.

During the outbreak investigation, the hosts informed the public health authority that half of their pigeons had fallen ill. The pigeons were then diagnosed as being infected with Salmonella by a veterinarian on the basis of their symptoms (the veterinarian did not conduct any laboratory tests on the pigeons). Due to the timing of the symptoms, it was assumed that the pigeons were also infected with Salmonella.

Given the laboratory results from the egg samples from the hosts laying hens and recommendation from the 
Cases of gastroenteritis among people who ate different types of cake at a family event, Warsaw, Poland, September $2011(n=48)$

\begin{tabular}{|c|c|c|c|c|c|c|}
\hline $\begin{array}{l}\text { Exposure to } \\
\text { angel cake }\end{array}$ & $\begin{array}{l}\text { By consumption } \\
\text { of cake type }\end{array}$ & Cases $^{a}$ & Total & AR (\%) & $\mathrm{RR}$ & $95 \% \mathrm{Cl}$ \\
\hline \multirow{2}{*}{ Yes } & Cream cake & 3 & 3 & 100 & \multirow{2}{*}{1.13} & \multirow{2}{*}{$0.96-1.32$} \\
\hline & No cream cake & 16 & 18 & 89 & & \\
\hline \multirow{2}{*}{ No } & Cream cake & 1 & 1 & 100 & \multirow{2}{*}{4.00} & \multirow{2}{*}{$2.00-8.00$} \\
\hline & No cream cake & 6 & 24 & 25 & & \\
\hline \multirow{2}{*}{ Yes } & Caramel cake & 2 & 2 & 100 & \multirow{2}{*}{1.12} & \multirow{2}{*}{$0.96-1.30$} \\
\hline & No caramel cake & 17 & 19 & 89 & & \\
\hline \multirow{2}{*}{ No } & Caramel cake $^{\mathrm{b}}$ & 0 & 0 & 0 & \multirow{2}{*}{-} & \multirow{2}{*}{-} \\
\hline & No caramel cake ${ }^{\text {b }}$ & 7 & 25 & 28 & & \\
\hline \multirow{2}{*}{ Yes } & Eclairs & 8 & 9 & 89 & \multirow[b]{2}{*}{0.97} & \multirow{2}{*}{$0.73-1.29$} \\
\hline & No éclairs & 11 & 12 & 92 & & \\
\hline \multirow{2}{*}{ No } & Eclairs & 6 & 14 & 43 & \multirow{2}{*}{4.71} & \multirow{2}{*}{$0.66-33.61$} \\
\hline & No éclairs & 1 & 11 & 9 & & \\
\hline
\end{tabular}

AR: attack rate; $\mathrm{Cl}$ : confidence interval; $\mathrm{RR}$ : relative risk.

a Probable $(n=14)$ and confirmed $(n=12)$.

b No RR yielded due to zeros present in this stratum.

veterinarian, the hosts took action: they agreed to cull the entire flock of 17 laying hens and the 40 ill pigeons assumed to be infected, remove their bodies from the premises and disinfect the entire area where the animals lived. The veterinarian provided treatment for the remaining 40 non-symptomatic pigeons.

\section{Discussion}

This gastroenteritis outbreak, which affected just under half (26 of 57 ) attendees of a family event, was linked to infected home-produced eggs from laying hens. Results from the outbreak investigation identified a number of factors that could have contributed towards its occurrence. These included the use of an unprocessed contaminated ingredient, inappropriate storage, cross-contamination and infection of food handlers [14].

The distribution of probable and confirmed cases suggested a point source food-borne outbreak. Epidemiological investigations pointed to angel cake as the vehicle of infection. S. Enteritidis is frequently isolated in products made using raw eggs [15-19]. The hosts used raw eggs knowing their hens had not been screened for Salmonella. The general public often consider organic [20] or free-range chickens more likely to be Salmonella free [21]. However, unless poultry are subject to checks, such assumptions cannot be made. The frequency with which such checks should be carried out and the methods that should be used are issues that raise a number of challenges. Any decision would have to take into account the following points: whether the outcome would result in a recommendation or a regulation, whether the focus should be on villages or individual farms; the age of the laying hens; and whether 'new' hens had been introduced into existing flocks, as well as the presence of other animals on the premises. Recommendations on the frequency of testing should be carefully evaluated especially in terms of cost-effectiveness and acceptability. They should also consider who would pay for screening or regulation. The debate would benefit from a panel of experts being called together, including those from the European Food Safety Authority, European Centre for Disease Prevention and Control and others involved in work with poultry and Salmonella. Such discussions would be pertinent, as use of raw eggs from flocks that are regularly screened for Salmonella could potentially have prevented the outbreak. Infections with Salmonella traced back to unscreened home-produced eggs emphasise the importance of screening laying hens in private residences.

The high attack rate $(52 \%, 34 / 65)$ in this outbreak could be attributed in part to the lack of refrigeration of dishes as they were stored at room temperature on a warm day. Lack of refrigeration allowed S. Enteritidis to grow, as previously documented in other outbreaks $[18,22,23]$. Had the dishes been refrigerated, the attack rate may have been reduced.

People who only ate cream cake from the desserts offered were four times more likely to develop symptoms (Table 3). This, along with the fact that the cakes 
were placed together on the same serving platter with a single knife, supports the hypothesis of cross-contamination. Furthermore, the hosts left all the cakes out on the table throughout the course of a warm afternoon, where the cakes could soften and mix with others. Cross-contamination is frequently reported in $S$. Enteritidis outbreaks $[23,24]$, particularly in places where large quantities of food are served $[17,25]$. We could not document a significant association between consumption of éclairs and illness; however, similar cross-contamination may explain why five cases who ate only éclairs for dessert also became ill.

Given the absence of left-over food specimens, we used phage typing to establish a link between consumption of angel cake and symptoms of Salmonella infection. $S$. Enteritidis PT21C was found, documenting its presence in Poland. This phage type is rare [22]. Phage typing is a key tool, used in outbreaks and as part of surveillance to assess the strains currently in circulation [4]. However, as this technique is not routinely performed in Poland, we cannot determine whether $\mathrm{PT} 21 \mathrm{C}$ is in frequent circulation in the country. Phage typing needs to be encouraged, particularly during outbreak investigations, in countries where case reports of Salmonella infection remain high. Other tools for subtyping $S$. Enteritidis include pulsed field gel electrophoresis (PFGE) [26] and multiple-locus variablenumber tandem-repeat analysis (MVLA) [27]. PFGE is considered to have low discriminatory power for $S$. Enteritidis, especially in outbreak settings [27]. MVLA has been shown to have better discriminatory power than phage typing or PFGE [28]; however, this technique for $S$. Enteritidis typing is not currently used at the National Institute of Public Health- National Institute of Hygiene in Warsaw.

\section{Study limitations}

Physicians did not take stool specimens from all people in the cohort. We therefore cannot rule out the possibility that other members of the cohort, particularly those who lived on the premises where the event was held, were asymptomatically infected with Salmonella. If they had been infected with the same strain, they should have been excluded from the cohort, as consumption of cake would not have affected them. In our cohort, we excluded all known asymptomatic infected people who had been tested (as they were food handlers or involved in food preparation for the event). Lack of identification and exclusion of any additional asymptomatic infected people would result in an underestimation of the strength of association we calculated. Thus, this limitation does not prevent us from concluding that the angel cake was the vehicle in this outbreak.

The small numbers in this outbreak limited interpretation of results from the analytical study, due to lack of power. Its findings, however, were indirectly supported and strengthened by the microbiological results.

\section{Conclusions}

Salmonella control activities, such as screening of laying hens, have helped decrease the number of cases of Salmonella infection reported in Poland; however, this outbreak points to gaps that still exist. Identifying home-produced eggs as the source of the outbreak indicates that privately owned hens are not adequately covered by measures in place. Furthermore, the high attack rate observed demonstrates the impact use of unscreened home-produced eggs can have in the population. This - along with surveillance data suggesting that home-produced eggs remain a common cause of outbreaks of Salmonella infection among humans in Poland [9] - calls for action. On the basis of our results, we suggest areas where changes to everyday practices could be of benefit. To bridge this gap in salmonellosis control, we need to actively engage the general public. First, the general public should ensure safety of their food through the use of screened eggs in dishes that require raw ingredients. Second, food items containing raw products should be kept and served separately. Third, products requiring refrigeration should be kept at low temperatures prior to consumption. In the context of outbreaks, phage typing is one of the tools that can be used to establish links between cases and sources, for example, in the absence of food items.

\section{Acknowledgments}

We would like to thank members of the outbreak team, particularly Teresa Karpińska, Marzena Czapczyk, Jolanta Krszyna and all the sanitary stations epidemiological departments in Otwock, Pruszków, Garwolin, Puławy and WarsawPraga for their collaboration. We also thank Dr Yvan Hutin, Dr loannis Karagiannis, Dr Michal Czerwiński and colleagues in the Department of Epidemiology at the National Institute of Public Health- National Institute of Hygiene for their helpful comments. 


\section{References}

1. European Centre for Disease Prevention and Control (ECDC). Annual epidemiological report 2011. Reporting on 2009 data and 2010 epidemic intelligence data. Stockholm: ECDC; 2011. Available from: http://ecdc.europa.eu/en/publications/ Publications/1111_SUR_Annual_Epidemiological_Report_on_ Communicable_Diseases_in_Europe.pdf

2. European Food Safety Authority (EFSA), European Centre for Disease Prevention and Control (ECDC). The European Union summary report on trends and sources of zoonoses, zoonotic agents and food-borne outbreaks in 2009. EFSA Journal. 2011;9(3):2090. Available from: http://www.efsa.europa.eu/ de/efsajournal/doc/2090.pdf

3. Mishu B, Griffin PM, Tauxe RV, Cameron DN, Hutcheson RH, Schaffner W. Salmonella Enteritidis gastroenteritis transmitted by intact chicken eggs. Ann Intern Med. 1991;115(3):190-4.

4. Fisher IS; Enter-net participants. Dramatic shift in the epidemiology of Salmonella enterica serotype Enteritidis phage types in western Europe, 1998-2003--results from the Enter-net international salmonella database. Euro Surveill. 2004;9(11):pii=486. Available from: http://www. eurosurveillance.org/ViewArticle.aspx?Articleld $=486$

5. Welby S, Imberechts H, Riocreux F, Bertrand S, Dierick K, Wildemauwe C, et al. Comparison of Salmonella Enteritidis phage types isolated from layers and humans in Belgium in 2005. Foodborne Pathog Dis. 2011; 8(8):929-34.

6. European Commission. Commission regulation (EU) No 517/2011 of 25 May 2011 implementing Regulation (EC) No 2160/2003 of the European Parliament and of the Council as regards a Union target for the reduction of the prevalence of certain Salmonella serotypes in laying hens of Gallus gallus and amending Regulation (EC) No 2160/2003 and Commission Regulation (EU) No 200/2010. Luxembourg: Publications Office of the European Union. 26.5.2011. L 138. Available from: http:// eur-lex.europa.eu/LexUriServ/LexUriServ.do?uri=0J:L:2011:138 :0045:0051:EN:PDF

7. European Food Safety Authority (EFSA), European Centre for Disease Prevention and Control (ECDC). The European Union summary report on trends and sources of zoonoses, zoonotic agents and food-borne outbreaks in the European Union in 2010. EFSA Journal. 2012;10(3):2597. Available from: http:// www.efsa.europa.eu/en/efsajournal/doc/2597.pdf

8. Regulation (EU) No 2160/2003 of the European Parliament and of the Council of 17 November 2003 on the control of salmonella and other specified food-borne zoonotic agents. Official Journal of the European Union. Luxembourg: Publications Office of the European Union. 12.12.2003:L 325. Available from: http://eur-lex.europa.eu/LexUriServ/ LexUriServ.do?uri=0):L:2003:325:0001:0015:EN:PDF

9. Baumann-Popczyk A, Sadkowska-Todys M. [Foodborne infection and intoxication, Poland in 2010]. Przegl Epidemiol. 2012; 66(2). Polish.

10. StataCorp. 2007. Stata statistical software: release 10. College Station, TX: StataCorp LP.

11. European Committee on Antimicrobial Susceptibility Testing (EUCAST). Breakpoint tables for interpretation of MICs and zone diameters. EUCAST; 2012. Available from: http:// www.eucast.org/fileadmin/src/media/PDFs/EUCAST_files/ Breakpoint tables/Breakpoint table_v_2.0_120221.pdf

12. Szych J, Cieślik A, Paciorek J, Kałużewski S. Antibiotic resistance In Salmonella enterica subsp. enterica strains isolated In Poland from 1998 to 1999. Int J Antimicrob Agents, 2001;18(1):37-42.

13. Ward LR, de Sa JD, Rowe B. A phage-typing scheme for Salmonella enteritidis. Epidemiol Infect. 1987;99(2):291-4

14. European Food Safety Authority (EFSA). Manual for reporting of food-borne outbreaks in the framework of Directive 2003/99/ EC from the year 2010. Supporting publication 2011;138. Parma: EFSA: 2011. Available from: http://www.efsa.europa. eu/en/supporting/doc/138e.pdf

15. Rodrigue DC, Tauxe RV, Rowe B. International increase in Salmonella enteritidis: a new pandemic? Epidemiol Infect.1990; 105(1): 21-7.

16. Telzak EE, Budnick LD, Greenberg MS, Blum S, Shayegani $M$, Benson CE, et al. A nosocomial outbreak of Salmonella enteritidis infection due to the consumption of raw eggs. N Engl J Med.1990; 323(6): 394-7.

17. Evans MR, Tromans JP, Dexter EL, Ribeiro CD, Gardner D. Consecutive salmonella outbreaks traced to the same bakery. Epidemiol Infect. 1996;116(2):161-7.

18. D'Argenio P, Romano A, Autorino F. An outbreak of Salmonella enteritidis infection associated with iced cake. Euro Surveill. 1999;4(2):pii=75. Available from: http://www.eurosurveillance. org/ViewArticle.aspx?Articleld $=75$
19. Mølbak K, Neimann J. Risk factors for sporadic infections with Salmonella enteritidis, Denmark, 1997-1999. Am J Epidemiol. 2002;156(7):654-61.

20. Williams CM. Nutritional quality of organic food: shades of grey or shades of green? Proc Nutr Soc. 2002;61(1):19-24.

21. Bailey JS, Cosby DE. Salmonella prevalence in free-range and certified organic chickens. J Food Prot. 2005;68(11):2451-3.

22. Frank C, Buchholz U, Maass M, Schröder A, Bracht KH, Domke PG, et al. Protracted outbreak of S. Enteritidis PT $21 \mathrm{C}$ in a large Hamburg nursing home. BMC Public Health. 2007;7:243.

23. Janmohamed K, Zenner D, Little C, Lane C, Wain J, Charlett A, et al. National outbreak of Salmonella Enteritidis phage type $14 \mathrm{~b}$ in England, September to December 2009: case-control study. Euro Surveill. 2011;16(15):pii=19840. Available from: http:// www.eurosurveillance.org/ViewArticle.aspx?Articleld $=19840$

24. Gillespie IA, O’Brien SJ, Adak GK, Ward LR, Smith HR. Foodborne general outbreaks of Salmonella Enteritidis phage type 4 infection, England and Wales, 1992-2002: where are the risks? Epidemiol Infect. 2005;133(5):795-801.

25. Schmid D, Schandl S, Pichler AM, Kornschober C, Berghold C, Beranek A, et al. Salmonella Enteritidis phage type 21 outbreak in Austria, 2005. Euro Surveill. 2006;11(2):pii=600. Available from: http://www.eurosurveillance.org/ViewArticle. aspx?Articleld $=600$

26. Centers for Disease Control and Prevention (CDC). Outbreak of Salmonella serotype Enteritidis infections associated with raw almonds--United States and Canada, 2003-2004. MMWR Morb Mortal Wkly Rep. 2004;53(22):484-7. Available from: http:// www.cdc.gov/mmwr/preview/mmwrhtml/mm53d604a1.htm

27. Beranek A, Mikula C, Rabold P, Arnhold D, Berghold C, Lederer I, et al. Multiple-locus variable-number tandem repeat analysis for subtyping of Salmonella enterica subsp. Enterica serovar Enteritidis. Int J Med Microbiol. 2009;299(1):43-51.

28. Boxrud D, Pederson-Gulrud K, Wotton J, Medus C, Lyszkowicz E, Besser I, et al. Comparison of multiple-locus variable-number tandem repeat analysis, pulsed-field gel electrophoresis, and phage typing for subtype analysis of Salmonella enterica serotype Enteritidis. I Clin Microbiol. 2007;45(2):536-43. 